Research Article

\title{
Effect of fructooligosaccharides on the physicochemical properties of sour cassava starch and baking quality of gluten-free cheese bread
}

\author{
Eduardo Rodriguez-Sandoval ${ }^{1}$, Célia M. Landi Franco ${ }^{2}$ and Katherine Manjarres-Pinzon ${ }^{3}$ \\ ${ }^{1}$ Department of Agricultural and Food Engineering, Faculty of Agricultural Science, Universidad Nacional de Colombia, \\ Sede Medellín, Antioquia, Colombia \\ ${ }^{2}$ Department of Food Engineering and Technology, UNESP - Universidade Estadual Paulista, São José do Rio Preto, \\ São Paulo, Brazil \\ ${ }^{3}$ Department of Food Engineering, Faculty of Engineering, Universidad del Valle, Cali, Valle del Cauca, Colombia
}

\begin{abstract}
The present research was undertaken to explore the influence of fructooligosaccharides (FOS) on the functional and thermal properties of sour cassava starch and the quality characteristics of gluten-free (GF) cheese bread. Fructooligosaccharides were used to replace sour cassava starch at substitution level of 9\% (SF1), 17\% (SF2), and 29\% (SF3). The functional and thermal properties of the starch-FOS mixtures were determined by the water absorption index (WAI), water solubility index (WSI), pasting profile analysis, thermal transition temperatures and enthalpy of gelatinization. Moreover, the GF cheese breads with starch-FOS mixtures were analyzed for height, diameter, weight, specific volume and dough moisture content. The sample with the highest FOS content (SF3) presented the lowest WAI (1.44), peak (62.4 rapid visco units (RVU), breakdown (53.4 RVU), final (13.8 RVU), and setback (4.9 RVU) viscosities, dough moisture content $(31.7 \%)$, and enthalpy of gelatinization $(9.5 \mathrm{~J} / \mathrm{g})$ and the highest WSI $(29.4 \%)$ and pasting temperature $\left(69.1^{\circ} \mathrm{C}\right)$. The height, diameter and specific volume of GF cheese bread samples made from sour cassava starch were $3.14 \mathrm{~cm}, 6.35 \mathrm{~cm}$, and $1.49 \mathrm{~cm}^{3} / \mathrm{g}$, respectively. The SF1 mixture samples resulted in a $3.01 \mathrm{~cm}$ height, $6.34 \mathrm{~cm}$ diameter, and $1.55 \mathrm{~cm}^{3} / \mathrm{g}$ specific volume. According to Brazilian food labeling regulations, the latter product cannot be categorized as "a good source" of fiber because the minimum level of fiber per portion was not reached.
\end{abstract}

\section{Keywords:}

Baking / Fructooligosaccharides / Gluten-free cheese bread / Physicochemical properties / Sour cassava starch

\section{Introduction}

Sour cassava starch is naturally fermented for 15-60 days, after which it is sun-dried; this type of starch has an excellent capacity for expansion during baking $[1,2]$. This modification

Correspondence: Professor Eduardo Rodríguez-Sandoval, CII 59 No. 63-02, B14, Of 303, Núcleo el Volador, Universidad Nacional de Colombia, Medellín, Antioquia, Colombia

E-mail: edrodriguezs@unal.edu.co

Fax: +57-4-4309147

Abbreviations: FOS, fructooligosaccharides; GF, gluten-free; WAI, water absorption index; WSI, water solubility index
Received: October 15, 2013

Revised: January 22, 2014

Accepted: January 23, 2014 
bread that is very popular in some South American countries (Colombia and Brazil) [1, 5]. GF cheese bread is made by blending mainly sour cassava starch, water or milk, cheese, salt, sugar, and fat. This product does not contain wheat flour; neither does it undergo yeast fermentation before baking. The dough is baked immediately after kneading without a rising or proofing time. The rising during baking does not involve a protein-gluten network or the production of carbon dioxide by yeast [1].

Despite its acceptance, GF cheese bread does not have a standard quality. Furthermore, there is no production technology defined by the great variety of optional ingredients. Several formulations are marketed and labeled as "cheese bread", which have different behaviors after cooking. Some sour cassava starches result in products that might not support the desirable alveolar structure for the dough. GF cheese bread can be found on the market with a firm, alveolar and dry mass or a soft, non-alveolar, and gummy mass [9]. Moreover, the shelf life is short ( $<5$ days), mostly due to the physical and sensory properties of this product.

There has been a lot of attention paid to specific types of dietary carbohydrates, such as fructooligosaccharides (FOS). These compounds present important physicochemical and physiological properties that are beneficial to the health of consumers and, for this reason, their use as food ingredients has increased rapidly, such properties include non-cariogenicity, a low calorific value, and the ability to stimulate the growth of beneficial bacteria in the colon [10]. Molecules that start with one glucose moiety, followed by fructose moieties, are also called oligofructoses or FOS. Oligofructoses can be obtained by partial enzymatic hydrolysis of inulin or by enzymatic synthesis from sucrose. These fibers are linear chains of fructose units, 2-10 in number. They are also considered a subcategory of inulins. This product is free of gluten, fat, protein, and phytic acid, and contains only very small (negligible) amounts of some minerals and salts. These carbohydrates are used either as supplements to foods or as macronutrient substitutes. As supplements, they are added mainly because of their nutritional properties. Adding FOS increases the dietary fiber content of the food. Fructooligosaccharides are used as a sugar substitute mainly in dairy and bakery products at levels that cause no intestinal discomfort. Daily doses of $10-15 \mathrm{~g}$ cause no significant discomfort. At higher doses, flatulence may cause discomfort [11].

There are growing concerns over the nutritional adequacy of the GF dietary pattern because it is often characterized by an excessive consumption of energy, proteins, and fats and a reduced intake of complex carbohydrates and dietary fiber [12]. GF baked goods are often low in fiber because wheat flour is usually substituted with commercial starches, which usually do not significantly contribute to the dietary fiber content. Consequently, the enrichment of GF baked products with dietary fiber seems to be necessary [13]. Some authors have studied the quality attributes of FOS enriched cookies, with successful results at lower and medium levels of sugar replacement $[14,15]$. Thus, the aim of this study was to evaluate the effect of FOS on the functional and thermal properties of sour cassava starch and the quality characteristics of GF cheese bread.

\section{Materials and methods}

\subsection{Materials}

Preliminary experiments were performed to establish a GF cheese bread formula with FOS, taking into account that a portion of this product should weigh $50 \mathrm{~g}$ and the FOS addition should be at least $3 \mathrm{~g}$ per portion $[16,17]$. Therefore, control GF cheese breads (S) were prepared with $100 \%$ sour cassava starch. GF cheese bread samples were enriched with FOS at levels of $9 \%$ (SF1), $17 \%$ (SF2), and $29 \%$ (SF3) of sour cassava starch replacement. The ingredients of the GF cheese bread were matured minas cheese (Patos de Minas, MG, Brazil), pre-cooked corn flour (PAN, Alimentos Polar, Bogotá, Colombia), margarine, sugar, salt, milk, and sour cassava starch, purchased in the local market (São Jose do Rio Preto, SP, Brazil), and FOS, provided by Corn Products (Nutra Flora P 95, Corn Products, Mogi Guaçu, SP, Brazil). Nutra Flora is synthesized enzymatically to generate fructooligosaccharide species consisting of a glucose $(G)$ monomer linked to two, three, or four fructose $(\mathrm{F})$ molecules. This product is referred to as the GFn type of FOS. In this case, the FOS contained $\mathrm{GF}_{2}(40.1 \%), \mathrm{GF}_{3}(48.6 \%)$ and $\mathrm{GF}_{4}(11.3 \%)$, and had a $\mathrm{pH}$ of 6.5 and a $2.6 \%$ moisture content, according to the product technical datasheet.

\subsection{Physicochemical properties of sour cassava starch and FOS}

The moisture content of the sour cassava starch and FOS were determined with a moisture analyzer (MX-50, A\&D, Tokyo, Japan). The water absorption index (WAI) and water solubility index (WSI) can be used as an indicative of starch modification due to a physical or chemical treatment. WAI measures the volume occupied by the starch granule after swelling in excess water, WSI determines the amount of free molecules leached out from the starch granule in excess water $[18,19]$. The WAI and WSI of the sour cassava starch (S) and starch-FOS mixtures (SF1, SF2, SF3) were determined by slightly modifying the method of Anderson et al. [20]. The sour cassava starch was sieved through a $0.177 \mathrm{~mm}$ mesh (Tyler 80, Granutest, São Paulo, SP, Brazil) to standardize the sample size. The samples $(2.5 \mathrm{~g})$ were weighed in centrifuge tubes $(50 \mathrm{~mL})$ using an analytical balance (Jex-200, YMC, Kyoto, Japan), mixed with $30 \mathrm{~mL}$ of distilled water and were vigorously agitated in a standard laboratory vortex shaker until complete dispersion and then placed in a stirred water 
bath (Marconi, Piracicaba, SP, Brazil) for $30 \mathrm{~min}$ at $30^{\circ} \mathrm{C}$. Then, the samples were centrifuged at $3000 \times \mathrm{g}$ for $10 \mathrm{~min}$ in a centrifuge (Jouan BR4i, Thermo Scientific, Milford, MA, USA). The supernatant liquid was poured carefully into a tared dish and evaporated in a fan oven (MA 035, Marconi, Piracicaba, SP, Brazil) at $100^{\circ} \mathrm{C}$ overnight. The precipitated gel was weighed and the WAI calculated from the initial and final weights. As an index of water solubility, the amount of dried solids recovered by evaporating the supernatant was expressed as a percentage of dry solids. All measurements were done in triplicate.

The pasting properties of the sour cassava starch, with and without FOS at the previously described substitution levels, were obtained using a Rapid Visco Analyzer (RVA-4, Newport Scientific, Warriewood, NSW, Australia). Each sample was added to $25 \mathrm{~mL}$ of distilled water to prepare a $6 \% \mathrm{w} / \mathrm{w} \mathrm{db}$ suspension. Each suspension was kept at $30^{\circ} \mathrm{C}$ for $1 \mathrm{~min}$, heated to $95^{\circ} \mathrm{C}$ at a rate of $6^{\circ} \mathrm{C} / \mathrm{min}$, held at $95^{\circ} \mathrm{C}$ for $5.5 \mathrm{~min}$, cooled to $50^{\circ} \mathrm{C}$ at a rate of $6^{\circ} \mathrm{C} / \mathrm{min}$ and finally held at $50^{\circ} \mathrm{C}$ for $2 \mathrm{~min}$. All the determinations were performed in duplicate [3].

The gelatinization properties of the samples were determined using a differential scanning calorimeter (DSC-Pyris 1, Perkin Elmer, Norwalk, CT, USA). The starch samples $(2 \mathrm{mg}, \mathrm{db}$ ) were weighed in aluminum pans, mixed with distilled water $(6 \mu \mathrm{L})$ and sealed. The fructooligosaccharides were added to $3 \mathrm{~mL}$ of distilled water and then $6 \mu \mathrm{L}$ of the solution were placed in aluminum pans, taking into account the FOS/starch mixtures. The weighed samples were kept at room temperature overnight to equilibrate and scanned at a rate of $10^{\circ} \mathrm{C} / \mathrm{min}$ over a temperature range of 25$100^{\circ} \mathrm{C}$. An empty pan was used as a reference. All the measurements were performed in triplicate [3].

\subsection{Preparation of gluten-free cheese bread}

The formulation was based on the amount of cheese (Table 1). The added milk (g) in the formulation depended mainly on the dough consistency. According to preliminary tests, the amount of milk added should result in a soft, cohesive, nonsticky and homogeneous GF cheese dough. The dry ingredients and the margarine were blended in a mixer

Table 1. Gluten-free cheese bread formulation

\begin{tabular}{lcc}
\hline Ingredients & Weight $(\mathrm{g})$ & Percentage $(\%)^{\mathrm{a})}$ \\
\hline Cheese & 200 & 100 \\
Sour cassava starch & 100 & 50 \\
Corn flour & 40 & 20 \\
Shortening & 40 & 20 \\
Sugar & 12 & 6 \\
Salt & 6 & 3 \\
\hline
\end{tabular}

a) Based on the amount of cheese.
(KitchenAid, St. Joseph, MI, USA) for $1 \mathrm{~min}$. Then, the grated cheese was added and blended for $2 \mathrm{~min}$. Finally, the milk was slowly added to develop a soft and homogeneous dough, which was divided into portions of $50 \mathrm{~g}$. Each portion was molded manually into a cylindrical shape $(5 \mathrm{~cm}$ diameter, $1.9 \mathrm{~cm}$ height). The cylindrical dough samples ( 8 units) were baked at $150^{\circ} \mathrm{C}$ for $15 \mathrm{~min}$ in an electric oven (Lyar, J y Ryal Co, Jundiaí, SP, Brazil).

\subsection{Physical measurements of gluten-free cheese bread}

The specific volume $\left(\mathrm{cm}^{3} / \mathrm{g}\right)$, weight $(\mathrm{g})$, height $(\mathrm{cm})$, and diameter $(\mathrm{cm})$ were measured in eight (8) GF cheese bread samples for each treatment. The dough moisture content was determined by drying $2.5 \mathrm{~g}$ of sample in a fan oven (MA 035, Marconi, Piracicaba, SP, Brazil) at $105^{\circ} \mathrm{C}$ for $4 \mathrm{~h}$ [21]. The bread specific bulk volume was determined by the millet displacement method. The loaf weight was recorded and the specific volume $\left(\mathrm{cm}^{3} / \mathrm{g}\right)$ was calculated [3].

\subsection{Statistical analysis}

One-way analysis of variance (amount of FOS in the formulation) was used in this study. The experimental data were analyzed by ANOVA at a 5\% significance level and least significant difference (LSD) was used to compare treatments when significant differences were found. The statistical analysis was performed using Statgraphics Plus 5.1. The data are given as means $\pm \mathrm{SD}$.

\section{Results and discussion}

\subsection{Functional and thermal properties}

The WAI and WSI of the sour cassava starch and the starchFOS mixtures are reported in Table 2. These parameters were significantly affected by the starch-FOS mixture $(p<0.05)$. The sour cassava starch presented the highest WAI value and the lowest WSI value; whereas, the SF3 samples showed the highest WSI value and the lowest WAI value. Water absorption was decreased by oligosaccharide addition, which is in agreement with results reported elsewhere [17, 22, 23]. The WAI reduction can be attributed to the fact that FOS form microcrystals when water is added, which interact, forming particle gel and leading to a smooth creamy texture. In contrast to other soluble fibers with high water-binding capacities, the macromolecules of FOS form junction zones and so absorb less water. The properties of oligosaccharides are based on water immobilization during the formation of these gel particles rather than actual water binding [17, 24].

On the other hand, the WSI greatly increased as the addition of FOS increased because oligosaccharides are water 
Table 2. WAI, WSI, and pasting properties of the sour cassava starch (S) and the FOS-starch mixtures

\begin{tabular}{|c|c|c|c|c|c|c|c|}
\hline \multirow[b]{2}{*}{ Sample } & \multirow[b]{2}{*}{ WAI $(g / g)$} & \multirow[b]{2}{*}{ WSI (\%) } & \multirow[b]{2}{*}{ Pasting Temp $\left({ }^{\circ} \mathrm{C}\right)$} & \multicolumn{4}{|c|}{ Viscosity (RVU) } \\
\hline & & & & Peak & Breakdown & Final & Setback \\
\hline$S$ & $3.46 \pm 0.06^{d}$ & $0.32 \pm 0.03^{\mathrm{a}}$ & $66.25 \pm 0.26^{\mathrm{a}}$ & $151.47 \pm 4.73^{\mathrm{d}}$ & $130.06 \pm 3.38^{d}$ & $33.97 \pm 1.99^{d}$ & $12.56 \pm 0.61^{\mathrm{d}}$ \\
\hline SF1 & $1.81 \pm 0.02^{\mathrm{C}}$ & $9.68 \pm 0.20^{b}$ & $66.93 \pm 0.23^{b}$ & $119.81 \pm 1.56^{\mathrm{c}}$ & $103.39 \pm 0.98^{c}$ & $25.50 \pm 0.82^{\mathrm{c}}$ & $9.08 \pm 0.17^{\mathrm{c}}$ \\
\hline SF2 & $1.68 \pm 0.01^{\mathrm{b}}$ & $17.43 \pm 0.04^{\mathrm{c}}$ & $67.55 \pm 0.09^{\mathrm{c}}$ & $96.33 \pm 1.62^{b}$ & $82.86 \pm 1.13^{b}$ & $20.31 \pm 0.46^{b}$ & $6.83 \pm 0.36^{\mathrm{b}}$ \\
\hline SF3 & $1.44 \pm 0.00^{\mathrm{a}}$ & $29.44 \pm 0.01^{\mathrm{d}}$ & $69.13 \pm 0.43^{\mathrm{d}}$ & $62.36 \pm 0.92^{\mathrm{a}}$ & $53.44 \pm 0.93^{\mathrm{a}}$ & $13.86 \pm 0.10^{\mathrm{a}}$ & $4.94 \pm 0.13^{\mathrm{a}}$ \\
\hline
\end{tabular}

Averages of three replicates per sample.

Values followed by the same letter in the same column are not significantly different $(p<0.05)$.

soluble [10] and, probably, there is no synergistic interaction between the sour cassava starch and FOS, which could increase the solubility of FOS. Zimeri and Kokini [25] found that the inulin-waxy maize starch system has two phases with completely different morphologies, confirming the presence of separate networks and the existence of phase separation. The fiber source and the type and degree of processing are the principal factors that influence the functional properties of high-fiber ingredients, viscosity, gelation, water-binding and oil-binding capacities, mineral and organic molecule binding $[26,27]$. The WAI and WSI of the samples were similar to the data reported elsewhere $[8,28,29]$, but lower compared to the data reported by Mestres et al. [30] and Marcon et al. [9], probably due to the different methods used in these studies.

The pasting profiles of the sour cassava starch and the starch-FOS mixtures are presented in Fig. 1 . The viscosity profile of the sour cassava starch was typical for this type of fermented starch, including a sharp rise in viscosity shortly after the pasting temperature, reaching the peak viscosity followed by a drop until it reached the trough viscosity and then gradually rising again to a slightly higher final viscosity $[3,4,31]$. The starch granules swelled and absorbed water (gelatinization), matching the first consistency increment; then, a viscosity reduction was observed and finally, in the last part of the curve, the cooling encompassed a slight consistency increase. This last increment in consistency was related to starch retrogradation [27]. The pasting profiles of the starch-FOS mixtures resulted in a behavior similar to that of the sour cassava starch; but with lower pasting viscosities as the FOS amount was increased (Fig. 1).

The pasting parameters of the sour cassava starch and the starch-FOS mixtures are summarized in Table 2. The peak, breakdown, final and setback viscosities of the sour cassava starch were significantly higher than those of starch-FOS mixtures; whereas, the pasting temperature of the sour starch was the lowest. The peak viscosity is also known as the gelatinization peak; a higher peak viscosity indicates a high amylopectin content (crystalline structure) [32]. Breakdown is an indication of how easily the granular structure of starch breaks. Likewise, final viscosity and setback are defined as the degree of re-association between the starch molecules, involving amylose or the transition from a viscous liquid to a gel $[33,34]$. These pasting viscosities were higher in the sour cassava starch, followed by SF1, SF2, and SF3, respectively. These results could be attributed to the high water solubility

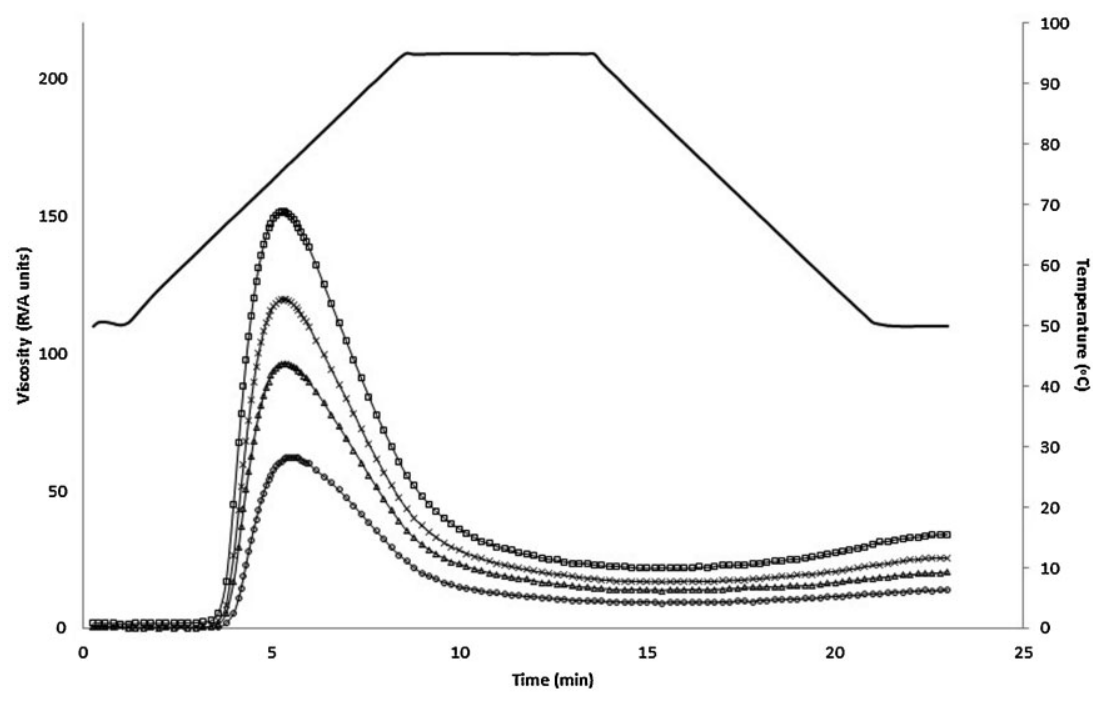

Figure 1. Pasting profiles of the sour cassava starch $(\square)$ and the FOS-starch mixtures at levels of $9 \%(\operatorname{SF} 1)(\times), 17 \%(\operatorname{SF} 2)(\Delta)$, and $29 \%$ (SF3) (O) sour cassava starch replacement. The results are displayed as viscosity in RVU. 
Table 3. Thermal properties of the sour cassava starch (S) and the FOS-starch mixtures

\begin{tabular}{lllll}
\hline Sample & $T_{0}\left({ }^{\circ} \mathrm{C}\right)$ & $T_{\mathrm{p}}\left({ }^{\circ} \mathrm{C}\right)$ & $T_{\mathrm{f}}\left({ }^{\circ} \mathrm{C}\right)$ & $\Delta H(\mathrm{~J} / \mathrm{g})$ \\
\hline S & $61.57 \pm 0.25^{\mathrm{a}}$ & $67.09 \pm 0.12^{\mathrm{a}}$ & $73.67 \pm 0.23^{\mathrm{a}}$ & $14.90 \pm 0.69^{\mathrm{b}}$ \\
SF1 & $62.38 \pm 0.21^{\mathrm{a}}$ & $67.76 \pm 0.24^{\mathrm{b}}$ & $73.91 \pm 0.16^{\mathrm{a}}$ & $14.45 \pm 0.57^{\mathrm{b}}$ \\
SF2 & $63.49 \pm 0.76^{\mathrm{b}}$ & $69.02 \pm 0.47^{\mathrm{c}}$ & $75.76 \pm 0.68^{\mathrm{b}}$ & $14.07 \pm 0.17^{\mathrm{b}}$ \\
SF3 & $66.16 \pm 0.30^{\mathrm{c}}$ & $71.11 \pm 0.11^{\mathrm{d}}$ & $76.73 \pm 0.11^{\mathrm{c}}$ & $9.50 \pm 0.43^{\mathrm{a}}$ \\
\hline
\end{tabular}

Averages of two replicates per sample.

Values followed by the same letter in the same column are not significantly different $(p<0.05)$.

of FOS and the lower starch content. This fiber was not able to modify the general trends defined by the sour cassava starch.

Gelatinization occurs over a temperature range because gelatinization involves different kinds of loss-of-order transitions and granules in a population from a single source are heterogeneous [35]. The fructooligosaccharides delayed the rapid initial increase in viscosity of the heated sour cassava starch suspensions, increasing the pasting temperature. This fiber may compete with starch for water due to its high solubility, delaying the start of gelatinization.

The thermal properties of the sour cassava starch and the starch-FOS mixtures are reported in Table 3. The values obtained for the thermal transition temperatures ( $T_{\mathrm{o}}=T$ onset, $T_{\mathrm{p}}=T$ peak, $T_{\mathrm{f}}=\mathrm{T}$ final) of the sour cassava starch were slightly lower than the results reported elsewhere [3, 7-9]. The enthalpy of gelatinization $(\Delta H)$ of the sour cassava starch was consistent with levels reported by Franco et al. [3] and Mestres and Rouau [36], but higher than those reported elsewhere [7-9].

The onset and the final temperatures of the sour cassava starch were similar to those of the SF1 sample, but lower than those of the SF2 and SF3 samples. Whereas, the peak temperature was lower in the sour cassava starch, followed by SF1, SF2, and SF3, respectively. The $\Delta H$ of the samples were not significantly affected by the addition of FOS, with the exception of the SF3 sample that resulted in the lowest value. Although the $\Delta H$ of the sour cassava starch and starch-FOS mixtures (SF1 and SF2) were statistically similar, a slight reducing tendency with the replacement of starch was observed. The $\Delta H$ of starch is related to the melting of the crystalline zone. The more the crystalline and the higher the starch content of a sample are, the larger the amount of energy that will be spent on melting those crystals [8].

\subsection{Baking quality characteristics}

The baking quality characteristics of the GF cheese bread from the sour cassava starch and starch-FOS mixtures are shown in Table 4. There were no significant differences in the height, diameter, added milk and specific volume of the GF cheese bread samples from those of the sour cassava starch and SF1 mixture. However, these baking characteristics of the sour cassava starch and SF1 samples were significantly higher than those of the SF2 and SF3 mixtures. Moreover, the dough moisture content was higher in samples from the sour cassava starch, followed by the SF1, SF2, and SF3 samples, respectively (Table 4).

The specific volume of GF cheese bread samples is an indicative of the baking expansion capacity of the starch used in this baking product. The specific volume of the samples was lower than those reported elsewhere [3-7, 9, 29, 37, 38]; due to the ingredients of the product and the process conditions used in these studies. Three major factors are involved in the expansion of sour cassava starch during baking. First, the driving force is represented by the steam pressure of the trapped water, which increases as the temperature increases, inducing bubble growth. Secondly, thermal transitions modify the thermomechanical properties of the dough. Finally, water loss gives rise to the characteristics of the crumb network, which depends on the dough permeability.

The existence of bubbles trapped within the gelatinized matrix of the sour cassava starch solution was evidenced by microscopic observation under heating [2]. Moreover, the fat content (from the cheese and/or the formulation) and the gelatinized starch may stabilize the gas bubble interface. During baking, fat crystals melt and make it possible for the crystal-liquid interface to be incorporated into the surface of the bubble as it expands. This transfer of interfacial material from crystals to a bubble surface explains how the addition of shortening to dough allows bubbles to expand during baking without rupturing [39]. The crumb network is achieved during the cooling period,

Table 4. Baking quality characteristics of the gluten-free cheese bread from the sour cassava starch (S) and the FOS-starch mixtures

\begin{tabular}{|c|c|c|c|c|c|}
\hline Sample & Height $(\mathrm{cm})$ & Diameter (cm) & Specific Volume $\left(\mathrm{cm}^{3} / \mathrm{g}\right)$ & Milk (g) & Dough moisture content (\%) \\
\hline$S$ & $3.14 \pm 0.20^{b}$ & $6.35 \pm 0.13^{b}$ & $1.49 \pm 0.03^{c}$ & $141.2 \pm 0.08^{c}$ & $38.30 \pm 0.12^{d}$ \\
\hline SF1 & $3.01 \pm 0.19^{b}$ & $6.34 \pm 0.10^{b}$ & $1.55 \pm 0.03^{c}$ & $140.7 \pm 0.86^{c}$ & $37.28 \pm 0.19^{c}$ \\
\hline SF2 & $2.34 \pm 0.35^{\mathrm{a}}$ & $6.29 \pm 0.03^{\mathrm{ab}}$ & $1.06 \pm 0.06^{b}$ & $118.8 \pm 1.70^{b}$ & $34.68 \pm 0.17^{b}$ \\
\hline SF3 & $2.01 \pm 0.00^{\mathrm{a}}$ & $6.09 \pm 0.03^{\mathrm{a}}$ & $0.77 \pm 0.14^{\mathrm{a}}$ & $100 \pm 0.05^{\mathrm{a}}$ & $31.69 \pm 0.20^{\mathrm{a}}$ \\
\hline
\end{tabular}

Averages of three replicates per sample.

Values followed by the same letter in the same column are not significantly different $(p<0.05)$. 
when the surface temperature becomes lower than the transition temperature of starch. During this phase, most of the water is evaporated, the steam pressure is stabilized and the crust is formed [2].

The samples with a higher FOS content (SF3 and SF2) did not expand during baking. Theses samples presented a lower WAI, dough moisture content, added milk, and a higher WSI and pasting and gelatinization temperature. As mentioned above, the driving force in expansion is water evaporation. If there is not enough water within the dough, the product expansion could be affected. Furthermore, the starch gelatinization at the beginning of baking induces partial solubilization and swelling and leads to the formation of a viscoelastic material. The latter can trap the gas being produced during baking, mainly before the formation of a rigid crust due to progressive dehydration, which can inhibit dough expansion. Thus, samples that present low gelatinization and pasting temperatures should have higher expansion during baking, before hardening of the crust [30]. The presence of non-starch material, particularly fiber, may also obstruct the formation of bubbles by disrupting the structure of the solid foam. The high solubilization capacity of FOS affected the starch gelatinization at the beginning of baking. Therefore, this situation decreases the possibility to form a suitable matrix that is able to trap gas produced by water in GF dough, decreasing the bubble growth caused by the steam pressure of the trapped water, before hardening of the sample crust. When performing the mass balance (calculations not shown), the SF3 formulation can be considered a fiber-rich product because this product $(50 \mathrm{~g})$ contained more than $3 \mathrm{~g}$ of FOS per portion [17]. The other two formulations, SF2 and SF1, had around 1 and $2 \mathrm{~g}$ of FOS content per portion, respectively. The baking quality characteristics of the SF3 samples were deficient compared to the control products.

\section{Conclusions}

The study revealed that GF cheese breads can be successfully formulated using FOS as a partial replacement for sour cassava starch at a (SF1) substitution level of $9 \%$. But according to Brazilian food labeling regulations, the latter product should not be considered a fiber-rich food because the minimum level of fiber per portion was not fulfilled. The WAI, peak, breakdown, final and setback viscosities and enthalpy of gelatinization of the sour cassava starch decreased as the partial replacement of sour cassava starch by FOS increased. Moreover, the physical properties of the FOS enriched GF cheese breads were affected in a negative way by demonstrating a decrease in height, diameter, specific volume, and dough moisture content. FOS, although interesting from a nutritional point of view, find little application in baking due to their technological effects. Further studies on the use of other additives, such as hydrocolloids, and on the micro images, texture properties, and sensory analysis of this product could aid in the search for suitable baking quality characteristics of FOS-enriched GF cheese breads.

AUIP is kindly acknowledged for providing a research grant to E. Rodriguez-Sandoval.

The authors have declared no conflict of interest.

\section{References}

[1] Dufour, D., Larsonneur, S., Alarcon, F., Brabet, C., Chuzel, G., in: Dufour, D., O'Brien, G., Best, R. (Eds.), Cassava Flour and Starch: Progress in Research and Development, CIRAD-SAR/ CIAT, Cali, Colombia 1996, pp. 133-141.

[2] Bertolini, A. C., Mestres, C., Raffi, J., Buleón, A. et al., Photodegradation of cassava and corn starches. J. Agric. Food Chem. 2001, 49, 675-682.

[3] Franco, C. M. L., Ogawa, C., Rabachini, T., Rocha, T. S. et al., Effect of lactic acid and UV irradiation on the cassava and corn starches. Braz. Arch. Biol. Technol. 2010, 53, 443-454.

[4] Bertolini, A. C., Mestres, C., Colonna, P., Rheological properties of acidified and UV-irradiated starches. Starch/ Stärke 2000, 52, 340-344.

[5] Demiate, I. M., Dupuy, N., Huvenne, J. P., Cereda, M. P., Wosiacki, G., Relationship between baking behavior of modified cassava starches and starch chemical structure determined by FTIR spectroscopy. Carbohydr. Polym. 2000, 42, 149-158.

[6] Dias, A. R. G., Zavareze, E. R., Elias, M. C., Helbig, E. et al., Pasting, expansion and textural properties of fermented cassava starch oxidised with sodium hypochlorite. Carbohydr. Polym. 2011, 84, 268-275.

[7] Vatanasuchart, N., Naivikul, O., Charoenrein, S., Sriroth, K., Molecular properties of cassava starch modified with different UV irradiations to enhance baking expansion. Carbohydr. Polym. 2005, 61, 80-87.

[8] Gomes, A. M. M., Mendes da Silva, C. E., Ricardo, N. M. P. S., Effects of annealing on the physicochemical properties of fermented cassava starch (Polvilho azedo). Carbohydr. Polym. 2005, 60, 1-6.

[9] Marcon, M. J. A., Kurtz, D. J., Raguzzoni, J. C., Delgadillo, I. et al., Expansion properties of sour cassava starch (Polvilho azedo): Variables related to its practical application in bakery. Starch/Stärke 2009, 61, 716-726.

[10] Crittenden, R. G., Playne, M. J., Production, properties and applications of food-grade oligosaccharides. Trends Food Sci. Technol. 1996, 7, 353-361.

[11] Coussement, P., Franck, A., in: Cho, S. S., Dreher, M. L. (Eds.), Handbook of Dietary Fiber, Marcel Dekker Inc., New York 2001, pp. 721-735.

[12] Thompson, T., Dennis, M., Higgins, L. A., Lee, A. R., Sharrett, M. K., Gluten free diet survey: are Americans with coeliac disease consuming recommended amounts of fibre, iron, calcium and grain foods? J. Hum. Nutr. Diet. 2005, 18, 163169.

[13] Sabanis, D., Lebesi, D., Tzia, C., Effect of dietary fibre enrichment on selected properties of gluten-free bread. $L W T$ Food Sci. Technol. 2009, 42, 1380-1389. 
[14] Gallagher, E., O'Brien, C. M., Scannell, A. G. M., Arendt, E. K., Evaluation of sugar replacers in short dough biscuit production. J. Food Eng. 2003, 56, 261-263.

[15] Handa, C., Goomer, S., Siddhu, A., Physicochemical properties and sensory evaluation of fructoligosaccharide enriched cookies. J. Food Sci. Technol. Mys. 2012, 49, 192199.

[16] RDC 359, Regulamento Técnico de Porções de Alimentos Embalados Para Fins de Rotulagem Nutricional, Agência Nacional de Vigilância Sanitária, Ministerio da Saudé, Brasil 2003.

[17] Hager, A. S., Ryan, L. A. M., Schwab, C., Gänzle, M. G. et al., Influence of the soluble fibres inulin and oat b-glucan on quality of dough and bread. Eur. Food Res. Technol. 2011, 232, 405-413.

[18] Collado, L. S., Mabesa, L. B., Oates, C. G., Corke, H., Bihontype noodles from heat-moisture-treated sweet potato starch. J. Food Sci. 2001, 66, 604-609.

[19] Ortiz, J. A. R., Carvalho, C. W. P., Ascheri, D. P. R., Ascheri, J. L. R., Andrade, C. T., Effect of sugar and water contents on non-expanded cassava flour extrudates. Ciênc. Tecnol. Aliment. 2010, 30, 205-212.

[20] Anderson, R. A., Conway, V. F., Pfeifer, V. F., Griffin, E. L., Gelatinization of corn grits by roll - and extrusion - cooking. Cereal Sci. Today 1969, 14, 4-12.

[21] Rodriguez-Sandoval, E., Fernández-Quintero, A., SandovalAldana, A., Cuvelier, G., Bello-Perez, L. A., Viscoelastic properties of reconstituted cassava dough. Int. J. Food Sci. Technol. 2009, 44, 138-144.

[22] Peressini, D., Sensidoni, A., Effect of soluble dietary fibre addition on rheological and breadmaking properties of wheat doughs. J. Cereal Sci. 2009, 49, 190-201.

[23] Wang, J., Rosell, C., Benedito de Barber, C., Effect of the addition of different fibres on wheat dough performance and bread quality. Food Chem. 2002, 79, 221-226.

[24] Williams, P. A., Phillips, G. O., in: Stephen, A. M. (Ed.), Food Polysaccharides and Their Application, Marcel Dekker Inc., New York 1995, pp. 463-500.

[25] Zimeri, J. E., Kokini, J. L., Morphological characterization of the phase behavior of inulin-waxy maize starch systems in high moisture environments. Carbohydr. Polym. 2003, 52, 225-236.

[26] Collar, C., Santos, E., Rosell, C. M., Assessment of the rheological profile of fibre-enriched bread doughs by response surface methodology. J. Food Eng. 2007, 78, 820-826.
[27] Angioloni, A., Collar, C., Significance of structuring/prebiotic blends on bread dough thermo-mechanical profile. Eur. Food Res. Technol. 2009, 229, 603-610.

[28] Nwokocha, L. M., Aviara, N. A., Senan, C., Williams, P. A., A comparative study of some properties of cassava (Manihot esculenta, Crantz) and cocoyam (Colocasia esculenta, Linn) starches. Carbohydr. Polym. 2009, 76, 362-367.

[29] Niba, L. L., Bokanga, M. M., Jackson, F. L., Schlimme, D. S., Li, B. W., Physicochemical properties and starch granular characteristics of flour from various Manihot esculenta (cassava) genotypes. J. Food Sci. 2001, 67, 1701-1705.

[30] Mestres, C., Boungou, O., Akissoë, N., Zakhia, N., Comparison of the expansion ability of fermented maize flour and cassava starch during baking. J. Sci. Food Agric. 2000, 80, 665-672.

[31] Abera, S., Rakshit, S. K., Comparison of physicochemical and functional properties of cassava starch extracted from fresh root and dry chips. Starch/Stärke 2003, 55, 287-296.

[32] Carvalho, C. W. P., Onwulata, C. I., Tomasula, P. M., Rheological properties of starch and whey protein isolate gels. Food Sci. Technol. Int. 2007, 13, 207-216.

[33] BeMiller, J. N., Pasting, paste, and gel properties of starchhydrocolloid combinations. Carbohydr. Polym. 2011, 86, 386-423

[34] Charles, A. L., Chang, Y. H., Ko, W. C., Sriroth, K., Huang, T. C., Some physical and chemical properties of starch isolates of cassava genotypes. Starch/Stärke 2004, 56, 413-418.

[35] Fredriksson, H., Silverio, J., Andersson, R., Eliasson, A.-C., Aman, P., The influence of amylose and amylopectin characteristics on gelatinization and retrogradation properties of different starches. Carbohydr. Polym. 1998, 35, 119134.

[36] Mestres, C., Rouau, X., Influence of natural fermentation and drying conditions on the physicochemical characteristics of cassava starch. J. Sci. Food Agric. 1997, 74, 147-155.

[37] Alvarado, P. M., Grosmaire, L., Dufour, D., Toro, A. G. et al., Combined effect of fermentation, sun-drying and genotype onbreadmaking ability of sour cassava starch. Carbohydr. Polym. 2013, 98, 1137-1146.

[38] Pereira, P. A. P., Ramos, T. M., Gajo, A. A., Gomes, U. J., Viability of using ricotta in preparation of cheese bread. Ciênc. Rural. 2010, 40, 2356-2360.

[39] Brooker, B. E., The role of fat in the stabilisation of gas cells in bread dough. J. Cereal Sci. 1996, 24, 187-198. 